Annales Geophysicae (2002) $20: 629-637$ (C) European Geophysical Society 2002

\title{
Monitoring magnetosheath-magnetosphere interconnection topology from the aurora
}

\author{
P. E. Sandholt ${ }^{1}$ and C. J. Farrugia ${ }^{2}$ \\ ${ }^{1}$ Department of Physics, University of Oslo, Oslo, Norway \\ ${ }^{2}$ Space Science Center, University of New Hampshire, Durham, New Hampshire, USA
}

Received: 28 June 2001 - Revised: 30 October 2001 - Accepted: 13 November 2001

\begin{abstract}
A strong southward rotation of the IMF ( $B_{Z}$ from 5 to $-6 \mathrm{nT}$ in $\sim 20 \mathrm{~s}$ ) on 4 January 1995 caused an abrupt reconfiguration of midday aurorae and plasma convection consisting of the following: (1) the red-line aurora associated with magnetosheath plasma transfer at the low-latitude magnetopause appeared at the same time that (2) the greenline aurora from precipitating energetic plasma sheet particles equatorward of the cusp (near the open-closed field line boundary) weakened visibly and shifted equatorward, (3) the high-latitude aurora during the previous northward IMF, which is associated with lobe reconnection, persisted briefly (3 $\mathrm{min}$ ) and brightened, before it disappeared from the fieldof-view, (4) the activation of a strong convection bay (DPY current) at cusp and sub-cusp latitudes when the field turned strongly south, (5) a distinct wave motion of the plasma sheet outer boundary, as inferred from the aurora, which correlates closely with Pc 5 magnetic pulsations. Our interpretation of the dramatic reconfiguration is that reconnection poleward of the cusp coexisted briefly with reconnection at sub-cusp latitudes. The latter provided a magnetic field connection which enabled, on the one hand, magnetosheath particles to enter and cause the red-line cusp aurora, and on the other hand, allowed for magnetospheric energetic particles to escape and weaken the outer plasma sheet source of the green-line emission. The coexistence of the two cusp auroras reflects the time required for one field line topology to replace another, which, under the prevailing high speed wind $(\sim 650 \mathrm{~km} / \mathrm{s})$, lasts $\sim 3-4 \mathrm{~min}$. The motion of open flux tubes propagating from equator to pole during this transition is traced in the aurora by a poleward moving form. The waves on the outer boundary of the plasma sheet are most likely due to the Kelvin-Helmholtz instability. The study illustrates the ability of local auroral observations to monitor even a global change in magnetospheric magnetic topology.
\end{abstract}

Key words. Magnetospheric Physics (auroral phenomena;

Correspondence to: P. E. Sandholt

(p.e.sandholt@fys.uio.no) magnetopause, cusp, and boundary layers; solar windmagnethoshere interactions)

\section{Introduction}

Through extensive observations of dayside aurorae monitored from the ground at Svalbard in combination with interplanetary data, it has recently been possible to classify the aurora as a function of interplanetary parameters (Sandholt et al., 1998b; Sandholt and Farrugia, 1999). Thus, it has been found that the IMF clock angle is an excellent organizing parameter. Similarly, however, the IMF clock angle appears also in in-situ observations at the magnetopause as the magnetic shear parameter (i.e. the rotation of the magnetic field across the magnetopause) to which the clock angle is approximately equal at low-latitudes (see Figs. 1 and 2 in Farrugia et al., 1998a). At the magnetopause it has been found that the shear angle determines whether the terrestrial and interplanetary magnetic fields are interconnected. Thus, for low magnetic shear, reconnection at the dayside low-latitudes is unlikely, and a plasma depletion layer forms adjacent to the sunward side of the magnetopause where the field piles up and the density decreases (Paschmann et al., 1978; Crooker et al., 1979; Paschmann et al., 1993; Phan et al., 1994). Instead, reconnection is likely to occur at high-latitudes, poleward of the cusp (Dungey, 1963; Crooker, 1979; Cowley, 1981).

When the shear at low-latitudes is high, evidence of local reconnection has been found repeatedly, in the form of high speed flows satisfying tangential momentum balance (Sonnerup et al., 1981), and bipolar signatures in the magnetic field component normal to the MP (Russell and Elphic, 1978). In the present report we are going to show that by monitoring the precipitation of particles of different energies at different latitudes, ground-based auroral observations are able to remote-sense the interconnectivity of the terrestrial and magnetosheath magnetic fields. 
We study an interval containing a sharp and strong IMF directional discontinuity (southward turn), separating a period of low clock angle from one of high clock angle. Indeed, aurorae appropriate to each of these separate states are identified and are seen to undergo abrupt changes (disappearance/appearance) at this IMF turning. Other phenomena, however, are observed to persist irrespective of the IMF transition, which we ascribe to the presence of an additional, viscous-type coupling process.

We shall be concerned with auroral observations in the midday sector at high-latitudes 11:00-12:00 MLT/ 70 $80^{\circ}$ MLAT. According to the classification of dayside auroral forms proposed by Sandholt et al. (1998b), the appropriate aurorae in the cusp region and to its equatorward side are the following. For small clock angles, the cusp aurora is typically located at $\sim 77^{\circ}-80^{\circ}$ MLAT and is characterized by a sharp poleward boundary. This aurora is accompanied by equatorward ("reverse") convection and is called type 2 (Sandholt et al., 1996, 1998a, 2001; Milan et al., 2000). For large clock angles, the cusp auroral form is typically located at $\sim 72^{\circ}-74^{\circ}$ MLAT, and is characterized by a sharp equatorward boundary (Sandholt and Farrugia, 1999). This aurora is accompanied by poleward (anti-sunward) convection and is called type 1 . From intensifications at its equatorward boundary, forms usually propagate poleward (poleward moving auroral forms; PMAFs) into the regime of mantle precipitation (Sandholt et al., 1993). Both types 1 and 2 aurorae are related to plasma transfer from the magnetosheath, at low and high latitudes, respectively. An additional dayside emission, strongly dominated by the green line at $557.7 \mathrm{~nm}$, is often found equatorward of the cusp, particularly in the pre-noon sector. This so-called type 3 emission is caused by precipitating particles of plasma sheet energies. In this paper, we shall report for the first time changes in all three auroral forms in response to a rapid southward IMF turning and discuss the associated change in magnetosheathmagnetosphere magnetic interconnection geometry. We shall also note a wavy profile of the poleward boundary of the plasma sheet aurora throughout the interval, which we ascribe to a viscous-type process.

\section{Observations}

Figure 1 shows interplanetary plasma and field parameters from the solar wind experiment (SWE) (Ogilvie et al., 1995) and the magnetic field investigation (MFI) (Lepping et al., 1995) on the Wind spacecraft. The data resolutions are $3 \mathrm{~s}$ (MFI) and $90 \mathrm{~s}$ (SWE). From top to bottom, the panels show the proton density, the bulk speed, temperature, dynamic pressure, the GSM $X, Y$, and $Z$ components of the magnetic field and its total strength, and the IMF clock angle (polar angle in the GSM $Y Z$ plane) for the period 07:45-08:45 UT on 4 January 1995 . Wind was located at $(97,-75,-7) R_{E}$.

The prominent feature of these data is the sharp southward turning at $\sim 08: 13 \mathrm{UT}$. While $B_{X}$ and $B_{Y}$ retain their polarities (except for a brief transition in $B_{X}$ ), the north-south com- ponent $\left(B_{Z}\right)$ undergoes a rotation from 5 to $-6 \mathrm{nT}$ (clock angle from $20^{\circ}$ to $170^{\circ}$ ) in just $20 \mathrm{~s}$. The solar wind is a high speed $(660 \mathrm{~km} / \mathrm{s})$ stream with steady parameters. A simple estimate of the wind-to-magnetopause delay, based on the normal direction of the large discontinuity and the solar wind speed, gives $13.5 \mathrm{~min}$, which is close to the $12 \mathrm{~min}$ delay implied by the auroral observations (see below). The IMF remained strongly south (clock angle $>135^{\circ}$ ) for only $5 \mathrm{~min}$, and after 08:22 UT (second vertical line) it fluctuates around an average value of $\sim 100^{\circ}$. During the $8 \mathrm{~min}$ interval after the southward turning, IMF $B_{Y}$ decreased steadily from zero to $-6 \mathrm{nT}$ (between vertical guidelines).

The two panels of Fig. 2 show red and green line observations of the aurora from a meridian scanning photometer (line of sight intensity vesus zenith angle) for the period 08:00-09:00 UT (11:00-12:00 MLT). Intensities are colourcoded as shown below each panel. In the red-line emission we observe first a band at $\sim 30^{\circ}-60^{\circ}$ north of zenith (NZ), persisting until 08:30 UT. This is the type 2 cusp aurora. At 08:26 UT, a second red-dominated cusp form appears at $20^{\circ}-$ $50^{\circ}$ south of zenith (SZ). This is the type 1 cusp aurora.

A transient form is seen propagating poleward (from $60^{\circ} \mathrm{SZ}$ to $50^{\circ} \mathrm{NZ}$ in the green-line panel) when the type $1 \mathrm{au}-$ rora first appears (see panel $b$ ). This event culminates with a strong brightening of the type 2 form at 08:28 UT (see panel a). The types 1 and 2 coexisted for $\sim 3-4 \mathrm{~min}$, after which the type 2 disappeared and only type 1 remained. Thereafter the type 1 form moves slowly poleward and at 08:37 UT, the cusp aurora splits into two branches, one located poleward and the other equatorward of zenith. This type of auroral bifurcation has been related to an intermediate range of clock angles (Sandholt et al., 1998b, 2001), such as that seen in this case. The northern branch is weaker, and the southern branch is subject to sporadic, intermittent brightenings recurring at 2-3 min intervals. The fine structure of these forms is revealed in the green-line panel.

South of the cusp is an aurora documented by the green line (very weak red line) indicating its high-energy source in the plasma sheet (see Introduction). This emission, located near the southern horizon (the green-line panel), is the type 3 aurora. This aurora disappears suddenly from the field-ofview at 08:26-08:27 UT when simultaneously the type 1 first appears. The type 3 aurora reappears in the field-of-view at a reduced intensity and thereafter pursues an intermittent appearance/disappearance in the field of view during the time when the cusp is bifurcated. With respect to the earlier interval (before 08:26UT), the poleward edge of the type 3 aurora is located also at lower latitudes (higher zenith angles). A visible gap (emission minimum) exists between the type 1 cusp emission and the type 3 plasma sheet aurora. Corrugations of the poleward boundary of the type 3 aurora are evident and are particularly regular during the IMF northward pointing phase (before 08:26 UT). These observations suggest that there are waves on the plasma sheet boundary (see discussion).

Before turning to the ground magnetometer data we give a summary of the location (in zenith angle) of the cusp au- 


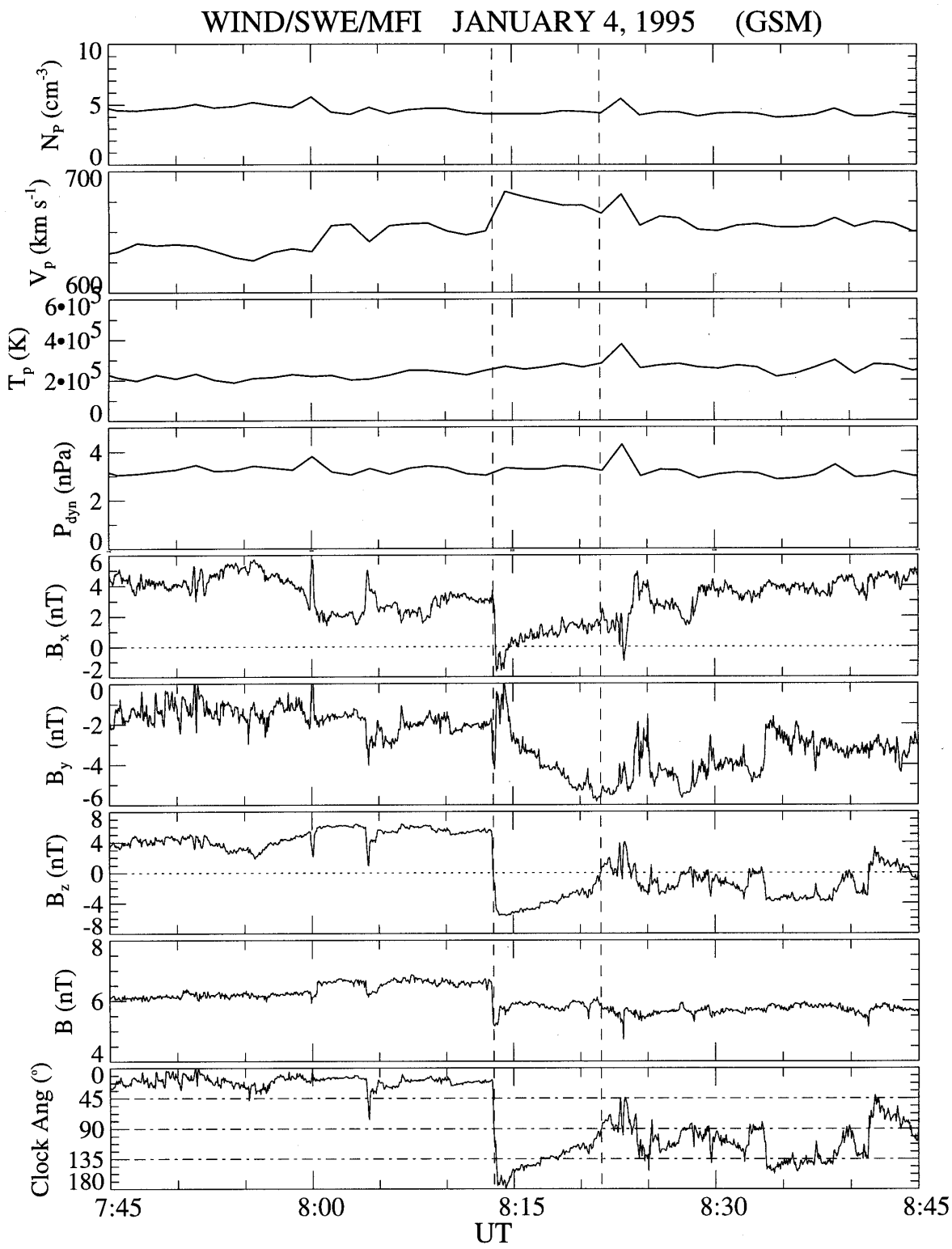

Fig. 1. Solar wind plasma and interplanetary magnetic field (IMF) data obtained from spacecraft WIND during the interval 07:45-08:45 UT on 4 January 1995. Panels from top to bottom show proton density, bulk speed, temperature, dynamic pressure, the GSM components of the magnetic field, the total field, and the IMF clock angle. The rapid southward turning at 08:13 UT (first vertical line) is the focus of this paper.

roral forms. (A) Before 08:26 UT: $30^{\circ}-60^{\circ} \mathrm{NZ}$ (type 2); (B) $08: 26-08: 30 \mathrm{UT}: 10^{\circ}-60^{\circ} \mathrm{NZ}$ (type 2), and $20^{\circ}-50^{\circ} \mathrm{SZ}$ (type 1); (C) 08:30-08:37 UT: $10^{\circ}-40^{\circ} \mathrm{SZ}$ (type 1); (D) 08:37 UT onwards: $0^{\circ}-40^{\circ} \mathrm{SZ}$ (type 1 ) and $15^{\circ}-45^{\circ} \mathrm{NZ}$ (type 2).

Figure 3 shows $X$ component magnetograms from the IMAGE stations on Svalbard (NAL-BJN) and north Norway (SOR and MAS), spanning the latitudinal range from $76^{\circ}$ to $66^{\circ}$ MLAT (see http://www.geo.fmi.fi/image/). An enhanced magnetic disturbance during the interval 08:26-08:35 UT is marked by vertical guidelines. This is a convection bay associated with the strongly southward IMF conditions recorded by Wind during 08:14-08:22 UT. The corresponding convec- tion current (Friis-Christensen and Wilhjelm, 1975) maximizes at the latitude of stations BJN (71.3 ${ }^{\circ}$ MLAT) and HOP (72.9 $9^{\circ}$ MLAT), well to the south of the optical site at NAL. The convection bay is accompanied by the presence of the type 1 aurora at the southernmost latitudes, before it is displaced slightly to the north around 08:35 UT (see Fig. 2). A convection current during the northward IMF phase, which is correlated with intensity modulations in the type 2 aurora, (see, for example, the the interval 08:20-08:25 UT), is reflected in the $X$ component trace at NAL (see discussion).

There are also magnetic oscillations in the Pc 5 range both before and after the southward IMF turning. (See, for example, the deflections at stations HOR-HOP-BJN, centered 


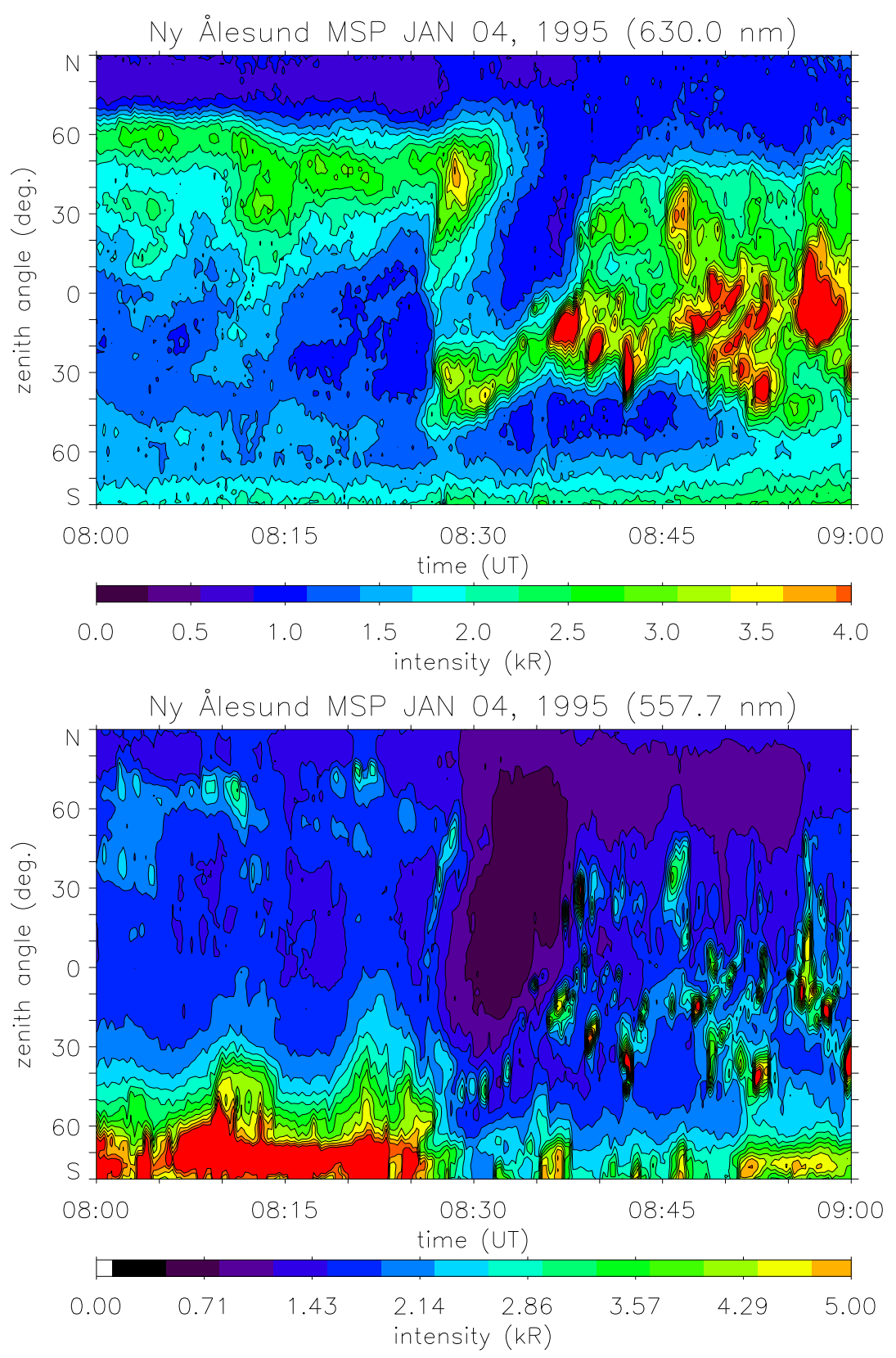

Fig. 2. Meridian scanning photometer observations from Ny Ålesund ( $76.1^{\circ}$ MLAT) of line of sight auroral intensities versus zenith angle at the two wavelengths 630.0 (panel (a) and $557.7 \mathrm{~nm}$ (panel (b) for 08:00-09:00 UT on 4 January 1995, North (N) is up. Intensities in kRs are colour-coded according to the scale at the bottom of each panel.

at $08: 13,08: 21,08: 36,08: 41$, and 08:46 UT.) They correspond to the wavy excursions of the plasma sheet poleward boundary.

\section{Discussion}

We have reported an IMF transition from a northward to a southward orientation and its consequences in both aurora and ionospheric convection, as inferred from ground observations. The schematics of Fig. 4 show the interconnection geometry appropriate to states before and after the abrupt IMF transition. The upper schematic shows reconnection occurring at high-latitudes, at an $X$-line $X_{H}$, appropriate to the interval 08:00-08:25 UT. The figure shows reconnected field lines contracting away from the $X$-line. The inwardpointing, solid arrows indicate magnetosheath plasma flowing Earthward along interconnected field lines, causing the high-latitude aurora labeled type 2 in the schematic. At lower latitudes is the closed field line region, the plasma sheet. Precipitation of this high-energy plasma produces the type 3 au- 


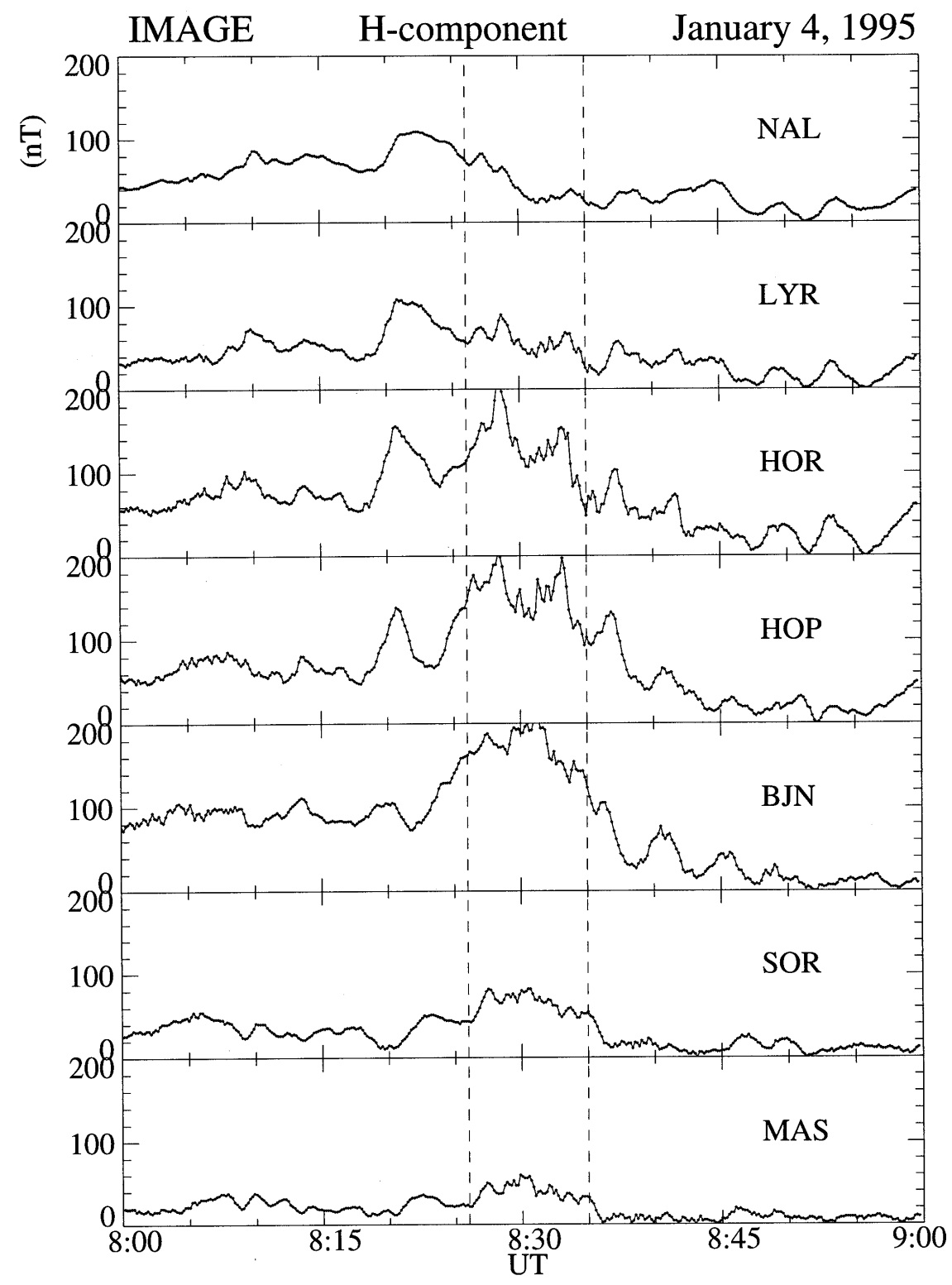

Fig. 3. $X$ component magnetograms from the IMAGE chain stations in NAL $\left(76.1^{\circ}\right.$ MLAT), LYR $\left(75.1^{\circ}\right.$ MLAT), HOR $\left(74.0^{\circ}\right.$ MLAT),

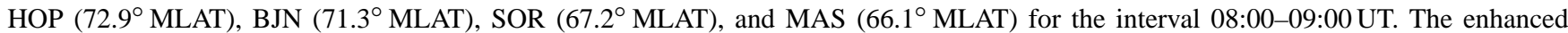
disturbance (convection bay), maximizing at BJN-HOP during 08:26-08:35 UT, is delimited by vertical guidelines.

rora located, as marked, equatorward of the type 2 aurora in this case.

In the lower schematic reconnection between the terrestrial field and the magnetosheath field occurs at $X_{L}$. Reconnected field lines are shown contracting poleward under a combination of magnetosheath flow and Maxwell tension forces on the bent field lines. These were previously closed magnetospheric field lines at the outer edge of the plasma sheet. Reconnection at $X_{L}$ produces two effects in the aurora: (1) magnetosheath particles can gain access to the magnetosphere along open field lines and when precipitating produce the cusp aurora of type 1, as labeled. This refers to the time interval 08:26-08:35 UT; (2) at the same time, energetic plasma sheet particles can escape to the magnetosheath (Scholer et al., 1982; Gosling et al., 1990), thereby depleting the source of the type 3 aurora at the outer boundary of the plasma sheet. Such events, characterized by equatorward shift of the open-closed field line boundary, are referred to in the literature as flux erosion events (Horwitz and Akasofu, 1977; Haerendel et al., 1978; Rijnbeek and Cowley, 1984), giving rise to inward contraction of the magnetopause and equatorward retreat of the type 3 aurora, as indicated by the open arrows in the figure. In the data, this is confirmed by the disappearance of the emission from the field-of-view in the southernmost part of the green line panel of Fig. 2 .

The gap between the types 1 and 3 aurorae ob- 

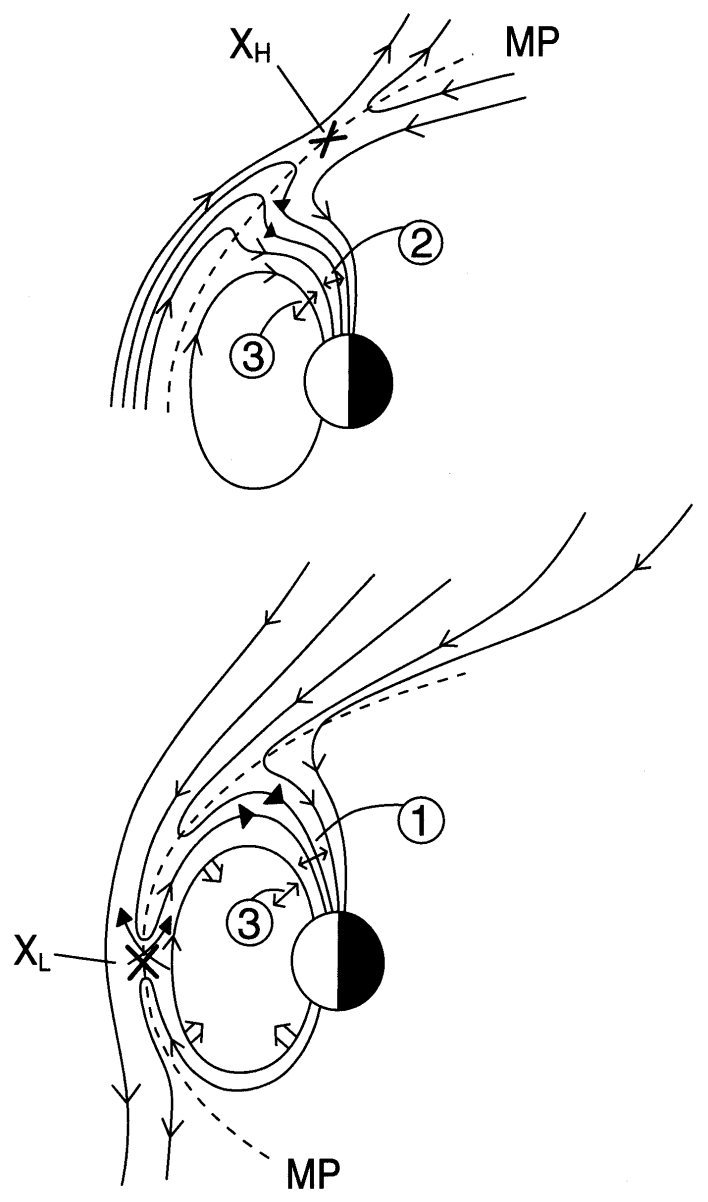

Fig. 4. Schematic illustration of magnetosheath-magnetosphere interconnection geometry for northward (top panel); and southward IMF orientation.

served after 08:26 UT most likely corresponds to the regime of low precipitation flux found just equatorward of the low-latitude boundary layer (LLBL) precipitation, which was labelled void in the statistical studies of Newell and Meng (1994). This is a signature of the escape of magnetospheric particles to the magnetosheath, along newly opened magnetic field lines (Lockwood, 1997).

The coexistence of the types 1 and 2 aurorae during 08:2608:30 UT indicates the time lapse from the appearance of $X_{L}$ to the disappearance of $X_{H}$, a time that is commensurate with the duration required for newly reconnected field lines at $X_{L}$ to reach $X_{H}$. Thus, it takes the magnetosphere of the order of 3-4 min in order to change its field line topology from one with field lines connected to the magnetosheath field at high-latitudes to one connected to the magnetosheath at low-latitudes. It corresponds to the time that is required for an open flux tube to contract from the subsolar region to the vicinity of the cusp under the action of Maxwell tension forces and magnetosheath flow. Recalling the fast solar wind in this example, this duration may be on the lower end of the time scale typical of such transitions. According to the estimate of Cowley (1982), this delay is about 5 min, which is in fairly good agreement with our observation, taking into account the fast solar wind ( $>600 \mathrm{~km} / \mathrm{s}$ ) in our case. The auroral signature of this transition is a poleward moving form tracing the footprint of flux tubes opened at low-latitudes as they move from $X_{L}$ to $X_{H}$.

When the clock angle is fluctuating around $100^{\circ}$ after 08:35 UT, both types 1 and 2 are present and subject to sporadic brightenings. This indicates that both $X$-lines are active. Due to the strong IMF $B_{Y}$ component, this would presumably occur in regions of near-antiparallel fields away from the noon-midnight plane (Sandholt et al., 2001).

The latitudinal gap between types 1 and 3 aurorae observed from 08:26:27 UT onwards also reflects the velocity filter effect on precipitating ions of magnetosheath origin. Since the magnetosheath plasma (ions and electrons) on open field lines is subject to a convection electric field, it precipitates at latitudes poleward of the projected merging line (open-closed field line boundary), due to the time-offlight effect and charge neutrality requirements (Rosenbauer et al., 1975; Burch, 1985; Onsager and Lockwood, 1997). The boundary between the type 3 (plasma sheet) aurora and the auroral gap (precipitation void) on its poleward side is a good indicator of the open-closed boundary (see discussion by Lockwood, 1997).

The event of enhanced convection during the $\sim 8 \mathrm{~min}$ long interval (08:13:14-08:21 UT) of negative IMF $B_{Z}$ is seen in the convection bay centered at latitudes $71^{\circ}-$ $74^{\circ}$ in Fig. 3. The schematics of Fig. 5 illustrates the aurora/convection conditions at three key times/intervals, 08:20-08:25 UT, 08:30 UT, and 08:45 UT corresponding, respectively, to times before, just after and well after the IMF north-south transition. At 08:20-08:25 UT, the two aurorae in the field-of-view are shown. The lower latitude aurora (type 3 ) is drawn with a wavy poleward boundary to reflect the meridian scanning photometer (MSP) observations of Fig. 2b. The type 2 aurora in the north is shown to be accompanied by lobe cell convection, characterized by equatorward/sunward flow at the polar cap boundary, as indicated by the heavy arrowed line. This so-called "reverse" convection is typical of strongly northward IMF (Maezawa, 1976; Crooker, 1992) and has been observed in the cusp aurora during very similar IMF conditions as those in the present case (Sandholt et al., 2000). The indicated southwestward convection in the vicinity of the optical site at $\mathrm{Ny}$ Ålesund (NAL) is consistent with the local magnetic deflection (positive $H$-component) recorded at NAL during 08:2008:30 UT, as shown in Fig. 3.

At 08:30 UT, the type 1 aurora has appeared to the south of the optical site. The type 3 form has retreated from the fieldof-view of the meridian scanner (double-arrowed, meridional line). The associated merging cell convection is indicated, distorted as shown due to IMF $B_{Y}<0$. The positive magnetic deflection (convection bay) at station BJN (Fig. 3) can be explained by the excitation of convection associated with a pulse of enhanced magnetopause reconnection, as de- 
scribed by Cowley and Lockwood (1992). This model predicts a westward return flow equatorward of the cusp during $B_{Y}<0$ conditions (see Fig. 1f in Lockwood et al., 1993) and (Fig. 4b in Cowley, 1998), which may explain the positive $H$-deflection at Bear Island (BJN; $71^{\circ}$ MLAT).

At 08:45 UT, the simultaneous presence of types 1 and 2 cusp aurorae (south and north of zenith, respectively) indicates a bifurcated cusp. At the southern field-of-view is the poleward boundary of the type 3 aurora. Convection is now a composite pattern of lobe (marked " $L$ ") and merging (" $M$ ") cells, consistent with the prediction of Reiff and Burch (1985) and the recent observations of Sandholt et al. (2001).

The presence of plasma sheet boundary waves of 5-10 min (Pc 5) is indicated by the latitudinal variation of the poleward boundary of the type 3 aurora when this emission is present (Fig. 2). A similar wave motion is present during both northward and southward IMF conditions, although the plasma sheet boundary when the IMF points south is displaced towards lower latitudes, near the boundary of the field-of-view of our optical instrument. These waves may be due to the Kelvin-Helmholtz instability acting at the interface between the low-latitude boundary layer and the plasma sheet. At this boundary there is typically not enough magnetic shear to stabilize the interface (Ogilvie and Fizenreiter, 1989). Thus, in this example, there is a viscous component to the magnetosphere-solar wind coupling, which is also monitored from the aurora.

Diffusive entry may be an additional source of the type 2 aurora during the northward IMF phase (Sandahl et al., 1997). Kelvin-Helmholtz waves are believed to be a major contributor to these diffusive processes (Sonnerup, 1980; Miura, 1984; Farrugia et al., 2001). This may also explain the intermittent presence (associated with the plasma sheet boundary waves) of weak, diffuse precipitation visible in the green-line emission in Fig. 2, for example, during the intervals 08:10-08:15 and 08:20-08:25 UT, at latitudes between those of the types 3 and 2 aurorae. Related to this we also note the intensity modulations in the type 2 aurora occurring in concert with the corrugations on the poleward boundary of the type 3 aurora (Fig. 2b). The amplitude of the boundary waves is apparently larger when the IMF is strongly north. This may be because the magnetopause and inner edge of the boundary layer are coupled and oscillate in phase. Such a situation for strongly northward IMF has been modeled (Farrugia et al., 1998b).

In summary, given that both the initial and final IMF states and the transition between them have such clear imprints in the aurora, one can reverse the correspondence and monitor global magnetospheric field line topology and its changes through the ground-based observations.

Acknowledgements. Part of this work was done when PES was on a research visit to the Space Science Center of the University of New Hampshire, Durham, NH. The IMAGE magnetometer data used in this paper were collected as a German-Finnish-Polish-Norwegian project conducted by the Technical University of Braunschweig and the Finnish Meteorological Institute. The auroral observation program on Svalbard is supported by the Norwegian Research Council

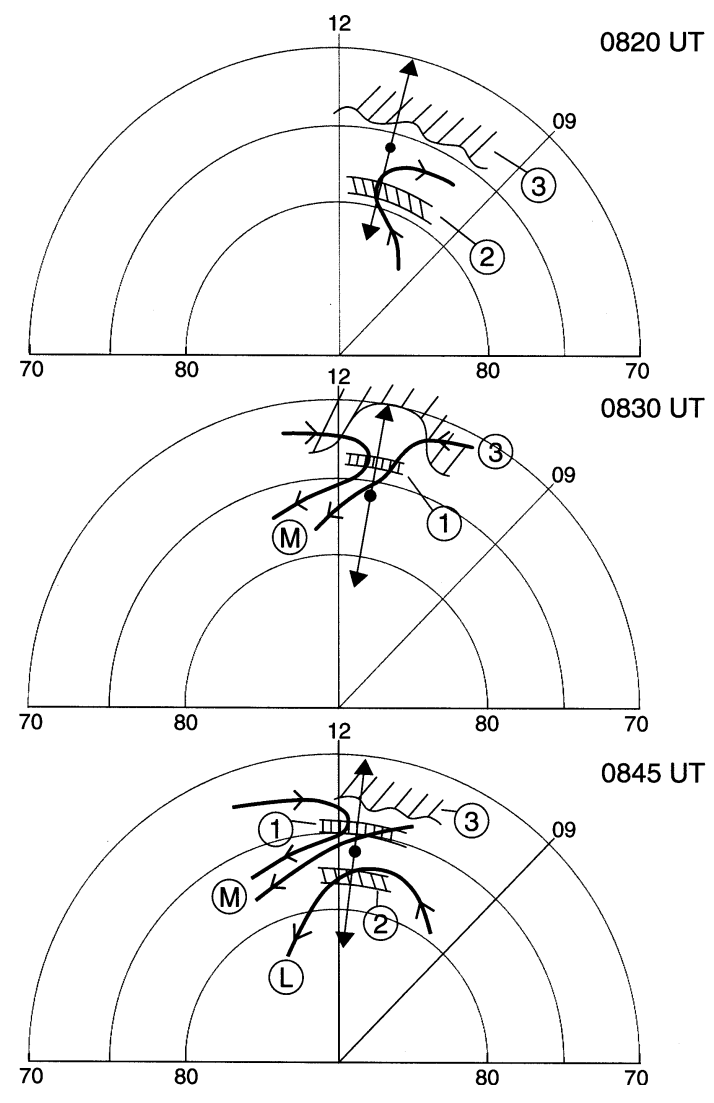

Fig. 5. Schematic illustration of plasma convection and aurora in MLAT-MLT coordinates for 08:20-08:25 UT (upper panel), 08:30 UT (middle panel), and 08:45 UT (lower panel). Different categories of auroral forms are labelled 1 and 2 (cusp types), and 3 (plasma sheet aurora). Plasma convection belonging to merging and lobe convection cells are marked $M$ and $L$, respectively. The field-of-view of the meridian scanning photometer in NyÅlesund (optical site; marked by solid dot) is indicated by double-arrowed meridional line.

and the Norwegian Polar Research Institute. This work was also supported by NASA grant NAG5-2834. Special thanks are due to Bjørn Lybekk for preparing the auroral data plots.

Topical Editor G. Chanteur thanks R. Rijnbeek and I. Stadsnes for their help in evaluating this paper.

\section{References}

Burch, J. L.: Quasi-neutrality in the polar cusp, Geophys. Res. Lett., 12, 469-472, 1985.

Cowley, S. W. H.: Magnetospheric and ionospheric flow and the interplanetary magnetic field, in: The Physical Basis of the Ionosphere in the Solar-Terrestrial System, no. 295 in Conference Proceedings, pp. 4-1-4-12, AGARD (Advisory Group for Aerospace Research \& Development), NATO, Neuilly sur Seine, France, 1981.

Cowley, S. W. H.: The causes of convection in the Earth's magnetosphere: a review of developments during the IMS, Rev. Geophys. Space Phys., 20, 531, 1982. 
Cowley, S. W. H.: Excitation of flow in the Earth's magnetosphereionosphere system: Observations by incoherent-scatter radar, in: Polar Cap Boundary Phenomena, (Eds) Moen, J., Egeland, A., and Lockwood, M., NATO ASI Series C, vol. 509, pp. 127-140, Kluwer Academic Publishers, Dordrecht, Holland, 1998.

Cowley, S. W. H. and Lockwood, M.: Excitation and decay of solar wind-driven flows in the magnetosphere-ionosphere system, Ann. Geophysicae, 10, 103, 1992.

Crooker, N. U.: Dayside merging and cusp geometry, J. Geophys. Res., 84, 951, 1979.

Crooker, N. U.: Reverse convection, J. Geophys. Res., 97, 19363, 1992.

Crooker, N. U., Eastman, T. E., and Stiles, G. S.: Observations of plasma depletion in the magnetosheath at the dayside magnetopause, J. Geophys. Res., 84, 869, 1979.

Dungey, J. W.: The structure of the exosphere or adventures in velocity space, in: Geophysics, The Earth's Environment, (Eds) De Witt, C., Hieblot, J., and Le Beau, L., p. 503, Gordon and Breach, New York, 1963.

Farrugia, C. J., Gratton, F. T., Bender, L., Quinn, J. M., Torbert, R. B., Erkaev, N. V., and Biernat, H. K.: Recent work on the Kelvin-Helmholtz instability at the magnetopause and boundary layer, in: Polar Cap Boundary Phenomena, vol. 509, pp. 1-14, Kluwer Academic Publishers, Dordrecht, Holland, 1998a.

Farrugia, C. J., Gratton, F. T., and Torbert, R.: Viscous-type processes in the solar wind-magnetosphere interaction, Space Sci. Rev., 95, 443, 2001.

Farrugia, C. J., Bender, F. T., Bender, L., Biernat, H. K., Erkaev, N. V., Quinn, J. M., Torbert, R. B., and Dennisenko, V.: Charts of joint Kelvin-Helmholtz and Rayleigh-Taylor instabilities at the dayside magnetopause for strongly northward interplanatary magnetic field, J. Geophys. Res., 103, 6703, 1998b.

Friis-Christensen, E. and Wilhjelm, J.: Polar cap currents for different directions of the interplanetary magnetic field in the $Y-Z$ plane, J. Geophys. Res., 80, 1248, 1975.

Gosling, J. T., Thomsen, M. F., Bame, S. J., Onsager, T. G., and Russell, C. T.: The electron edge of the low latitude boundary layer during accelerated flow events, Geophys. Res. Lett., 17, 1833, 1990.

Haerendel, G., Paschmann, G., Sckopke, N., Rosenbauer, H., and Hedgecock, P. C.: The frontside boundary layer and the problem of reconnection, J. Geophys. Res., 83, 3195, 1978.

Horwitz, J. and Akasofu, S.-I.: The response of the dayside aurora to sharp northward and southward transitions of the interplanetary magnetic field and to magnetospheric substorms, J. Geophys. Res., 82, 2723, 1977.

Lepping, R. P., Acũna, M. H., Burlaga, L. F., Farrell, W. M., Slavin, J. A., Schatten, K. H., Mariani, F., Ness, N. F., Neubauer, F. M., Whang, Y. C., Byrnes, J. B., Kennon, R. S., Panetta, P. V., Scheifele, J., and Worley, E. M.: The WIND magnetic field investigation, Space Sci. Rev., 71, 207-229, 1995.

Lockwood, M.: Relationship of dayside auroral precipitations to the open-closed separatrix and the pattern of convective flow, J. Geophys. Res., 102, 17 475, 1997.

Lockwood, M., Carlson, H. C., and Sandholt, P. E.: Implications of the altitude of transient 630-nm dayside auroral emissions, J. Geophys. Res., 98, 15 571, 1993.

Maezawa, K.: Magnetospheric convection induced by positive and negative $Z$-component of the interplanetary magnetic field: Quantitative analysis using polar cap magnetic records, J. Geophys. Res., 81, 2289, 1976.

Milan, S., Lester, M., Cowley, S. W. H., and Brittnacher, M.: Day- side convection and auroral morphology during an interval of northward interplanetary magnetic field, Ann. Geophysicae, 18, 436, 2000.

Miura, A.: Anomalous transport by magnetohydrodynamic KelvinHelmholtz instabilities in the solar wind-magnetosphere interaction, J. Geophys. Res., 89, 801, 1984.

Newell, P. T. and Meng, C. I.: Ionospheric projection of magnetospheric regions under low and high solar wind pressure conditions, J. Geophys. Res., 99, 273, 1994.

Ogilvie, K. W. and Fizenreiter, R. J.: The Kelvin - Helmholtz instability at the magnetopause and inner boundary layer surface, J. Geophys. Res., 94, 15 113, 1989.

Ogilvie, K. W., Chornay, D. J., Fritzenreiter, R. J., Hunsaker, F., Keller, J., Lobell, J., Miller, G., Scudder, J. D., Sittler, Jr., E. C., Torbert, R. B., Bodet, D., Needell, G., Lazarus, A. J., Steinberg, J. T., Tappan, J. H., Mavretic, A., and Gergin, E.: SWE, a comprehensive plasma instrument for the WIND spacecraft, Space Sci. Rev., 71, 55-77, 1995.

Onsager, T. G. and Lockwood, M.: High-latitude particle precipitation and its relationship to magnetospheric boundaries, Space Sci. Rev., 80, 77, 1997.

Paschmann, G., Sckopke, N., Haerendel, G., Papamastorakis, J., Bame, S. J., Asbridge, J. R., Gosling, J. T., Hones, E. W., and Tech, E. R.: ISEE plasma observations near the subsolar magnetopause, Space Sci. Rev., 22, 717, 1978.

Paschmann, G., Baumjohann, W., Sckopke, N., Phan, T., and Luhr, H.: Structure of the dayside magnetopause for low magnetic shear, J. Geophys. Res., 98, 13 409, 1993.

Phan, T.-D., Paschmann, G., Baumjohann, W., Sckopke, N., and Luhr, H.: The magnetosheath region adjacent to the dayside magnetopause: AMPTE/IRM observations, J. Geophys. Res., 99, 121, 1994.

Reiff, P. H. and Burch, J. L.: IMF $B_{Y}$-dependent plasma flow and Birkeland currents in the dayside magnetosphere, 2, A global model for northward and southward IMF, J. Geophys. Res., 90, 1595, 1985.

Rijnbeek, R. P. and Cowley, S. W. H.: Magnetospheric erosion events are flux transfer events, Nature, 309, 5964, 1984.

Rosenbauer, H., Grunwaldt, H., Montgomery, M. D., Paschmann, G., and Sckopke, N.: Heos-2 plasma observations in the distant polar magnetosphere: The plasma mantle, J. Geophys. Res., 80, 2723, 1975.

Russell, C. T. and Elphic, R. C.: Initial ISEE magnetometer results: Magnetopause observations, Space Sci. Rev., 22, 681, 1978.

Sandahl, I., Lundin, R., Yamauchi, M., Eklund, U., Safrankova, J., Nemecek, Z., Kudela, K., Lepping, R. L., Lin, R. P., Lutsenko, V. N., and Sauvaud, J.-A.: Cusp and boundary layer observations by INTERBALL, Adv. Space Res., 20, 823, 1997.

Sandholt, P. E. and Farrugia, C. J.: On the dynamic cusp aurora and IMF $B_{Y}$, J. Geophys. Res., 104, 12 461, 1999.

Sandholt, P. E., Moen, J., Rudland, A., Opsvik, D., Denig, W. F., and Hansen, T.: Auroral event sequences at the dayside polar cap boundary for positive and negative interplanetary magnetic field $B_{Y}$, J. Geophys. Res., 98, 7737, 1993.

Sandholt, P. E., Farrugia, C. J., Stauning, P., Cowley, S. W. H., and Hansen, T.: Cusp/cleft auroral forms and activities in relation to ionospheric convection: Responses to specific changes in solar wind and interplanetary magnetic field conditions, J. Geophys. Res., 101, 5003, 1996.

Sandholt, P. E., Farrugia, C. J., Moen, J., and Cowley, S. W. H.: Dayside auroral configurations: Responses to southward and northward rotations of the interplanetary magnetic field, J. Geo- 
phys. Res., 103, 20 279, 1998a.

Sandholt, P. E., Farrugia, C. J., Moen, J., Noraberg, O., Lybekk, B., Sten, T., and Hansen, T.: A classification of dayside auroral forms and activities as a function of IMF orientation, J. Geophys. Res., 103, 23 325, 1998b.

Sandholt, P. E., Farrugia, C. J., Cowley, S. W. H., Lester, M., Denig, W. F., Cerisier, J.-C., Milan, S. E., Moen, J., Trondsen, E., and Lybekk, B.: Dynamic cusp aurora and associated pulsed reverse convection during northward IMF, J. Geophys. Res., 105, 12869 , 2000.

Sandholt, P. E., Farrugia, C. J., Cowley, S. W. H., and Lester, M.: Dayside auroral bifurcation sequence during $B_{Y}$-dominated in- terplanetary magnetic field: Relationship with merging and lobe convection cells, J. Geophys. Res., 106, 15 429, 2001.

Scholer, M., Hovestadt, D., Ipavich, F. M., and Gloeckler, G.: Energetic protons, alpha particles, and electrons in magnetic flux transfer events, J. Geophys. Res., 87, 2169, 1982.

Sonnerup, B. U. O.: Theory of the low latitude boundary layer, J. Geophys. Res., 85, 2017, 1980.

Sonnerup, B. U. O., Paschmann, G., Papamastorakis, I., Sckopke, N., Haerendel, G., Bame, S. J., Asbridge, J. R., Gosling, J. T., and Russell, C. T.: Evidence for magnetic reconnection at the Earth's magnetopause, J. Geophys. Res., 86, 10 049, 1981. 